This is the accepted manuscript of the article, which has been published in Experimental dermatology. 2019, Vol. 28(2), 202-206. https://doi.org/10.1111/exd.13851

DR. TERO AH JÄRVINEN (Orcid ID : 0000-0002-4027-1759)

Article type : Concise Communications

\title{
R-RAS REGULATES VASCULAR PERMABILITY, BUT NOT OVERALL HEALING IN SKIN WOUNDS
}

Tuomo Ketomäki ${ }^{1, \#}$, Maria Vähätupa ${ }^{1, \#}$, Ulrike May ${ }^{1, \#}$, Toini Pemmari ${ }^{1}$, Ella Ruikka ${ }^{1}$, Jussi Hietamo $^{1}$, Pirkka Kaipiainen ${ }^{1}$, Harlan Barker ${ }^{1}$, Seppo Parkkila ${ }^{1,2}$, Hannele UusitaloJärvinen $^{1,2} \&$ Tero A.H. Järvinen ${ }^{1,2, *}$

${ }^{1}$ Faculty of Medicine and Life Sciences, University of Tampere, Tampere, Finland

${ }^{2}$ Fimlab laboratories, Eye Centre \& Department of Orthopedics \& Traumatology, Tampere University Hospital, Tampere, Finland

\# Equal contribution

*Address for correspondence:

Prof. Tero Järvinen, M.D., Ph.D.

Faculty of Medicine and Life Sciences

FI-33014 University of Tampere

Finland

Phone: $\quad+358-44-2854620$

This article has been accepted for publication and undergone full peer review but has not been through the copyediting, typesetting, pagination and proofreading process, which may lead to differences between this version and the Version of Record. Please cite this article as doi: 10.1111/exd.13851

This article is protected by copyright. All rights reserved. 
Fax: $\quad+358-3-35518450$

Email: blteja@uta.fi

\title{
Declarations of interest: none
}

\begin{abstract}
Wounds close by keratinocytes migrating from the edge of the wound and re-epithelializing the epidermis. It has been proposed that the major stimuli for wound closure are bloodderived growth factors, chemokines, and cytokines. The small GTPase R-Ras, a known integrin activator, also regulates vascular permeability during angiogenesis, and blood vessels lacking R-Ras leak plasma proteins constantly. We explored whether the access to bloodderived proteins influences skin wound healing in R-Ras knockout (KO) mice. In skin wounds, R-Ras expression was mostly restricted to the vasculature in the granulation tissue. Angiogenic blood vessels in the R-Ras KO mice were significantly more permeable than in wild-type (WT) controls. Although the distances between epidermal tongues, and the panniculus carnosus muscles, were significantly longer in R-Ras KO than WT controls before the granulation tissue formation took place, there were no differences in the wound closure or re-epithelialization rates or granulation tissue formation. These findings were also corroborated in a special splint excision wound model. Our study shows that although R-Ras does not influence the skin wound healing itself, but the blood vessels lacking R-Ras are leaky and thus could facilitate the access of blood-derived proteins to the wound.
\end{abstract}


Key Words: R-Ras, integrin, angiogenesis, wound, vascular permeability

\section{Background}

When skin is wounded, migration of epidermal keratinocytes at the wound edge initiates within hours, whereas migration of dermal fibroblasts toward the wounded area occurs several days later ${ }^{[1]}$. The cells of the newly wounded skin experience a dramatic microenvironmental transition where they are exposed to blood-derived growth factors, chemokines, and cytokines for the first time ${ }^{[1]}$. It has been discovered that epidermal and dermal cells respond differently to the exposure to blood ${ }^{[1-3]}$, which explains why keratinocyte migration takes place immediately after wounding, whereas it takes several days for dermal fibroblasts to be activated ${ }^{[1,2]}$.

R-Ras is a small GTPase of the Ras family of oncogenes ${ }^{[4-6]}$. Despite the close structural similarity to known oncogenes of the Ras family, the function of R-Ras is distinct from other Ras proteins ${ }^{[4]}$. Whereas all other members of the Ras family cause malignant transformation, R-Ras has very little or no transforming activity ${ }^{[4,5,7]}$. Furthermore, the opposing functions of R-Ras and other Ras members extend to cell adhesion, differentiation, and signaling ${ }^{[5,8,9]}$. These opposing functions suggest that the balance between R-Ras and other Ras members acts as a switch that controls proliferation and migration versus quiescence in cells ${ }^{[4,10]}$. The generation of R-Ras knockout $(\mathrm{KO})$ mice revealed a key function for R-Ras in regulating vascular permeability during angiogenesis in such diseases as cancer and diabetic retinopathy ${ }^{[4,10-15]}$. 


\section{Question addressed}

As angiogenic blood vessels lacking R-Ras leak blood-derived proteins, we explored whether the enhanced blood vessel leakiness in R-Ras KO mice influences wound healing.

\section{Experimental Design}

We explored the role of R-Ras in skin wound healing using R-Ras KO mice and two different wound healing models. All animal experiments were performed in accordance with protocols approved by the National Animal Ethics Committee of Finland. Vascular permeability assay, histology, immunohistochemistry, quantitative analysis of histology, morphological assessment of wound closure, computational expression analysis of R-Ras, animal care and

genotyping were performed using standard methods ${ }^{[14,16-21]}$ and are described in detail in the Supplementary data set.

\section{Results}

To elucidate the potential function of R-Ras in skin wound healing, we first performed comprehensive analysis of RNA-Seq data using the FANTOM5 (Functional ANnoTation Of the Mammalian genome) consortium gene expression data ${ }^{[22]}$, and retrieved the organspecific expression pattern from the Genotype-Tissue Expression (GTEx) database ${ }^{[23]}$. Two CAGE (Cap Analysis of Gene Expression) peaks were identified for RRAS. For both RRAS CAGE peaks, the expression was the highest in pericyte, smooth muscle, keratinocyte, fibroblast, and endothelial samples while being substantially lower for neutrophil, B cell, CD8, whole blood, macrophage, and monocyte samples, while organ-specific expression pattern indicates R-Ras expression being confined mainly to arteries (Suppl. Fig. S1). As the 
most comprehensive cDNA sequencing analysis yielded potential hits for RRAS gene expression in different cell types occupying skin wounds, we then studied the presence of RRas protein by immunohistochemistry in normal skin and during different stages of wound healing. Strong R-Ras expression was detected in angiogenic capillaries and larger blood vessels in the granulation tissue when the wound healing had progressed (from day 7 on) and in the dermal blood vessels of normal skin (Suppl. Fig. S2A-C). Some R-Ras expression was observed outside of the blood vessels in the granulation tissue (Suppl. Fig. S2). Doublestainings of R-Ras with markers for endothelial, keratinocyte, smooth muscle cell, myofibroblast and fibroblasts were conducted. These experiments revealed that R-Ras is expressed in blood vessels by endothelial cells, and smooth muscle cells (Suppl. Fig. S3A, D). Most epidermal keratinocytes do not express R-Ras in normal skin or in wound, but we could detect very few, random epidermal cells that seem to express it (Suppl. Fig. S3B). RRas was also expressed by very few cells in the granulation tissue that are positive for $\alpha \mathrm{SMA}$ and fibronectin, indicating that these cells are myofibroblasts and fibroblasts, respectively (Suppl. Fig. S3C, E). Strong R-Ras expression persisted in the blood vessels of the granulation tissue throughout the wound maturation process.

R-Ras has been recently proposed as a master regulator of vascular permeability in pathological angiogenesis associated with diseases, such as cancer and diabetic retinopathy [4,12-14]. To address whether it also regulates vascular permeability in physiological angiogenesis of the skin wound, the vascular leakage was quantified by measuring Evans Blue (EB) dye extravasation from circulation to wound granulation tissue. The R-Ras KO skin wounds had approximately a $100 \%$ increase in the EB leakage than the wild-type (WT) skin wounds at day $7(P=0.002)$ (Fig. 1E). 
It has been proposed that the "plasma $>$ serum>plasma" transition during wound repair controls wound closure and re-epithelialization ${ }^{[1]}$. Thus, we hypothesized that the lack of RRas might enhance wound healing by increasing the availability of natural growth factors from the blood, as the blood vessels lacking R-Ras could leak blood-derived proteins throughout the healing process. We could not see any difference in the wound closure rate between the WT and R-Ras KO mice (Fig. 1) (for n-values, see Suppl. Table S1). Next, we analyzed wound re-epithelialization at different time points during the healing process. Although the gap between the hyperproliferative epidermal tongues was larger in the R-Ras KO than WT mice at day 2, we could not see any difference between the WT and R-Ras KO mice at the end of the re-epithelialization process at day 7 (Fig. 1D \& Suppl. Fig. S4). We also determined the wound contraction by the length of the wound and the distance between the panniculus carnosus muscles and saw that both were significantly longer in the R-Ras KO than in the WT mice at day 2 (Suppl. Fig. S4). However, both of these values were identical in all later time points between the WT and KO mice (Suppl. Fig. S4). There was no difference in the size of granulation or scar tissue between the R-Ras KO and WT mice at any time point (Fig. 1C).

In rodents, wound closure can occur in two different ways: wound contraction and true reepithelialization ${ }^{[17,18]}$. As there were significant differences in the wound healing at day 2 (especially in the distance between panniculus carnosus muscles), but not in later time points, it could be assumed that R-Ras $\mathrm{KO}$ mice have a defect in wound contraction that is compensated by faster re-epithelialization. Thus, we decided to explore the relationship between wound contraction and re-epithelialization by employing a special skin excision wound model, where a round silicone splint issutured into the skin to firmly attach the underlying dermis and subcutis, to alleviate wound closure by contraction ${ }^{[16-18]}$. No difference in wound closure (i.e. wound size) was found under these special conditions 
between WT and R-Ras KO mice (Fig. 2A, B). Neither could we detect any differences between WT and R-Ras KO mice in re-epithelialization (both the gap remaining without epidermis and the length of epidermal tongues were identical) or in the size of granulation tissue (Fig. 2C, D, E, F).

\section{Conclusions}

Skin wound closure is achieved by re-epithelialization and is thought to be stimulated by stromal cells exposed to blood-derived growth factors after the wounding caused rupture of blood vessels and subsequent bleeding to the injured area ${ }^{[1,2]}$. We show here that the small GTPase R-Ras controls vascular permeability during skin wound healing, thus wounds lacking R-Ras would be constantly supplied by blood-derived proteins. Although wound reepithelialization was delayed in $\mathrm{R}-\mathrm{Ras} \mathrm{KO}$ at day 2, we show no difference in all other time points during wound healing process between WT and R-Ras KO mice, indicating that R-Ras does not play a significant role in skin wound healing. Despite employing both excision and splint wound models, one needs to acknowledge that rodent wound models do not perfectly recapitulate human wound healing ${ }^{[24,25]}$. Thus, certain limitations are warranted for the interpretation of our results.

Recently, it was demonstrated that R-Ras could be important for skin as it was required for tumor development in an experimental skin cancer model driven by inflammation ${ }^{[7]}$. However, R-Ras did not contribute directly to the transformation of epidermal cells to tumor cells as it was never expressed by these cells ${ }^{[7]}$. Instead, it promoted tumor progression by being required for both the induction of pro-inflammatory cytokine production and extravasation of inflammatory cells to the skin despite being expressed only in the blood vessels in the skin ${ }^{[7]}$. Although cytokines and inflammatory cells possess crucial roles in 
tissue regeneration and wound repair, we could not identify any role for R-Ras in skin wound healing.

Prior to this study, we postulated that the vascular hyperpermeability in R-Ras KO mice would provide constant exposure of blood-derived growth factors to wounds to influence the healing process. We tried to quantify by ELISA some of the growth factors implicated in the blood-derived stimuli of wound closure ${ }^{[1-3]}$, but could not detect them from wound lysates, which is in line with the short half-life of growth factors in the protease-rich milieu of the wound $^{[26]}$. Then we tried a proteomics-based approach ${ }^{[27]}$, but no growth factors were among the detected proteins. This finding is in line with the fact that a $30 \mathrm{kDa}$ dialysis cutoff value was used in the processing of tissue samples for proteomics ${ }^{[27]}$. Most recent data have shown that R-Ras is also crucial for lumenization of new capillaries and microvessels in ischemic conditions ${ }^{[28]}$. Most of the angiogenic blood vessels develop without lumen in ischemic skeletal muscle in R-Ras KO mice and the capillaries do not provide oxygen and nutrients for tissue regeneration ${ }^{[28]}$. Thus, the phenotype of $\mathrm{R}-\mathrm{Ras} \mathrm{KO}$ vasculature in angiogenesis, hyperpermeability, but lack of lumenization of capillaries ${ }^{[28]}$, could mean that the potential gain obtained by having blood-derived growth factors available is offset by the reduced supply of oxygen and nutrients.

Despite controlling the vascular permeability of the angiogenic blood vessels in skin wounds, thus controlling the exposure of blood-derived proteins to the wound bed, and showing a difference in wound re-epithelialization at day 2 , R-Ras did not influence skin wound healing in mice. 


\section{References}

[1] B. Bandyopadhyay, J. Fan, S. Guan, Y. Li, M. Chen, D.T. Woodley, W. Li, J. Cell Biol. 2006, 172, 1093-1105.

[2] Y. Li, J. Fan, M. Chen, W. Li, D.T. Woodley, J. Invest. Dermatol. 2006, 126, 2096-2105.

[3] A. Han, B. Bandyopadhyay, P. Jayaprakash, I. Lua, D. Sahu, M. Chen, D.T. Woodley, W. Li, Biol. Open. 2012, 1, 1169-1177.

[4] J. Sawada, M. Komatsu, Cell. Cycle. 2012, 11, 4285-4286.

[5] W.N. Liu, M. Yan, A.M. Chan, Cancer Lett. 2017, 403, 59-65.

[6] S. Nakhaei-Rad, F. Haghighi, P. Nouri, S. Rezaei Adariani, J. Lissy, N.S. Kazemein Jasemi, R. Dvorsky, M.R. Ahmadian, Crit. Rev. Biochem. Mol. Biol. 2018, 53, 130-156.

[7] U. May, S. Prince, M. Vähätupa, A.M. Laitinen, K. Nieminen, H. Uusitalo-Järvinen, T.A. Järvinen, Sci. Rep. 2015, 5, 11663.

[8] Z. Zhang, K. Vuori, H. Wang, J.C. Reed, E. Ruoslahti, Cell. 1996, 85, 61-69.

[9] P.D. Arora, T. He, K. Ng, C.A. McCulloch, Mol. Biol. Cell. 2018, mbcE18030147.

[10] M. Komatsu, E. Ruoslahti, Nat. Med. 2005, 11, 1346-1350.

[11] J. Sawada, F. Li, M. Komatsu, J. Biol. Chem. 2015, 290, 8133-8145.

[12] H. Ichimiya, K. Maeda, A. Enomoto, L. Weng, M. Takahashi, T. Murohara, Biochem. Biophys. Res. Commun. 2015, 461, 260-267.

[13] J. Sawada, T. Urakami, F. Li, A. Urakami, W. Zhu, M. Fukuda, D.Y. Li, E. Ruoslahti, M. Komatsu, Cancer. Cell. 2012, 22, 235-249.

[14] M. Vähätupa, S. Prince, S. Vataja, T. Mertimo, M. Kataja, K. Kinnunen, V. Marjomäki, H. Uusitalo, M. Komatsu, T.A. Järvinen, H. Uusitalo-Järvinen, Invest. Ophthalmol. Vis. Sci. 2016, 57, 4898-4909.

[15] C.Y. Perrot, J. Sawada, M. Komatsu, FASEB J. 2018, fj201700818RRR.

[16] H. Barker, M. Aaltonen, P. Pan, M. Vähätupa, P. Kaipiainen, U. May, S. Prince, H. Uusitalo-Järvinen, A. Waheed, S. Pastorekova, W.S. Sly, S. Parkkila, T.A. Järvinen, Exp. Mol. Med. 2017, 49, e334.

[17] L. Chen, R. Mirza, Y. Kwon, L.A. DiPietro, T.J. Koh, Wound Repair Regen. 2015, 23, 874-877.

[18] J.M. Davidson, F. Yu, S.R. Opalenik, Adv. Wound. Care. (New Rochelle). 2013, 2, $142-$ 148. 
[19] T.A. Järvinen, E. Ruoslahti, Proc. Natl. Acad. Sci. U. S. A. 2010, 107, 21671-21676.

[20] L. Kummola, Z. Ortutay, M. Vähätupa, S. Prince, H. Uusitalo-Järvinen, T.A.H. Järvinen, I.S. Junttila, Immun. Inflamm. Dis. 2017, 5, 280-288.

[21] T.A. Järvinen, E. Ruoslahti, Am. J. Pathol. 2007, 171, 702-711.

[22] FANTOM Consortium and the RIKEN PMI and CLST (DGT), A.R. Forrest, H. Kawaji, M. Rehli, J.K. Baillie, M.J. de Hoon, V. Haberle, T. Lassmann, I.V. Kulakovskiy, M. Lizio, M. Itoh, R. Andersson, C.J. Mungall, T.F. Meehan, S. Schmeier, N. Bertin, M. Jorgensen, E. Dimont, E. Arner, C. Schmidl, U. Schaefer, Y.A. Medvedeva, C. Plessy, M. Vitezic, J. Severin, C. Semple, Y. Ishizu, R.S. Young, M. Francescatto, I. Alam, D. Albanese, G.M. Altschuler, T. Arakawa, J.A. Archer, P. Arner, M. Babina, S. Rennie, P.J. Balwierz, A.G. Beckhouse, S. Pradhan-Bhatt, J.A. Blake, A. Blumenthal, B. Bodega, A. Bonetti, J. Briggs, F. Brombacher, A.M. Burroughs, A. Califano, C.V. Cannistraci, D. Carbajo, Y. Chen, M. Chierici, Y. Ciani, H.C. Clevers, E. Dalla, C.A. Davis, M. Detmar, A.D. Diehl, T. Dohi, F. Drablos, A.S. Edge, M. Edinger, K. Ekwall, M. Endoh, H. Enomoto, M. Fagiolini, L. Fairbairn, H. Fang, M.C. Farach-Carson, G.J. Faulkner, A.V. Favorov, M.E. Fisher, M.C. Frith, R. Fujita, S. Fukuda, C. Furlanello, M. Furino, J. Furusawa, T.B. Geijtenbeek, A.P. Gibson, T. Gingeras, D. Goldowitz, J. Gough, S. Guhl, R. Guler, S. Gustincich, T.J. Ha, M. Hamaguchi, M. Hara, M. Harbers, J. Harshbarger, A. Hasegawa, Y. Hasegawa, T. Hashimoto, M. Herlyn, K.J. Hitchens, S.J. Ho Sui, O.M. Hofmann, I. Hoof, F. Hori, L. Huminiecki, K. Iida, T. Ikawa, B.R. Jankovic, H. Jia, A. Joshi, G. Jurman, B. Kaczkowski, C. Kai, K. Kaida, A. Kaiho, K. Kajiyama, M. Kanamori-Katayama, A.S. Kasianov, T. Kasukawa, S. Katayama, S. Kato, S. Kawaguchi, H. Kawamoto, Y.I. Kawamura, T. Kawashima, J.S. Kempfle, T.J. Kenna, J. Kere, L.M. Khachigian, T. Kitamura, S.P. Klinken, A.J. Knox, M. Kojima, S. Kojima, N. Kondo, H. Koseki, S. Koyasu, S. Krampitz, A. Kubosaki, A.T. Kwon, J.F. Laros, W. Lee, A. Lennartsson, K. Li, B. Lilje, L. Lipovich, A. Mackay-Sim, R. Manabe, J.C. Mar, B. Marchand, A. Mathelier, N. Mejhert, A. Meynert, Y. Mizuno, D.A. de Lima Morais, H. Morikawa, M. Morimoto, K. Moro, E. Motakis, H. Motohashi, C.L. Mummery, M. Murata, S. Nagao-Sato, Y. Nakachi, F. Nakahara, T. Nakamura, Y. Nakamura, K. Nakazato, E. van Nimwegen, N. Ninomiya, H. Nishiyori, S. Noma, S. Noma, T. Noazaki, S. Ogishima, N. Ohkura, H. Ohimiya, H. Ohno, M. Ohshima, M. Okada-Hatakeyama, Y. Okazaki, V. Orlando, D.A. Ovchinnikov, A. Pain, R. Passier, M. Patrikakis, H. Persson, S. Piazza, J.G. Prendergast, O.J. Rackham, J.A. Ramilowski, M. Rashid, T. Ravasi, P. Rizzu, M. Roncador, S. Roy, M.B. Rye, E. Saijyo, A. Sajantila, A. Saka, S. Sakaguchi, M. Sakai, H. Sato, S. Savvi, A. Saxena, C. Schneider, E.A. Schultes, G.G. Schulze-Tanzil, A. Schwegmann, T. Sengstag, G. Sheng, H. Shimoji, Y. Shimoni, J.W. Shin, C. Simon, D. Sugiyama, T. Sugiyama, M. Suzuki, N. Suzuki, R.K. Swoboda, P.A. 't Hoen, M. Tagami, N. Takahashi, J. Takai, H. Tanaka, H. Tatsukawa, Z. Tatum, M. Thompson, H. Toyodo, T. Toyoda, E. Valen, M. van de Wetering, L.M. van den Berg, R. Verado, D. Vijayan, I.E. Vorontsov, W.W. Wasserman, S. Watanabe, C.A. Wells, L.N. Winteringham, E. Wolvetang, E.J. Wood, Y. Yamaguchi, M. Yamamoto, M. Yoneda, Y. Yonekura, S. Yoshida, S.E. Zabierowski, P.G. Zhang, X. Zhao, S. Zucchelli, K.M. Summers, H. Suzuki, C.O. Daub, J. Kawai, P. Heutink, W. Hide, T.C. Freeman, B. Lenhard, V.B. Bajic, M.S. Taylor, V.J. Makeev, A. Sandelin, D.A. Hume, P. Carninci, Y. Hayashizaki, Nature. 2014, 507, 462-470.

[23] GTEx Consortium, Nat. Genet. 2013, 45, 580-585. 
[24] S. Elliot, T.C. Wikramanayake, I. Jozic, M. Tomic-Canic, J. Invest. Dermatol. 2018, $138,736-740$.

[25] D.M. Ansell, C. Marsh, L. Walker, M.J. Hardman, K. Holden, J. Invest. Dermatol. 2018, 138, 994-997.

[26] G.C. Gurtner, S. Werner, Y. Barrandon, M.T. Longaker, Nature. 2008, 453, 314-321.

[27] M. Vähätupa, J. Nättinen, A. Jylhä, U. Aapola, M. Kataja, P. Kööbi, T.A.H. Järvinen, H. Uusitalo, H. Uusitalo-Järvinen, Invest. Ophthalmol. Vis. Sci. 2018, 59, 3294-3306.

[28] F. Li, J. Sawada, M. Komatsu, Nat. Commun. 2017, 8, 1720.

\section{Acknowledgements}

The authors thank Marianne Karlsberg, Anni Laitinen, and Marja-Leena Koskinen for practical support and histochemical work, Prof. Erkki Ruoslahti (Sanford Burnham Prebys Medical Discovery Institute, La Jolla, CA, USA) for providing the R-Ras knockout mice, Dr. Masanobu Komatsu (SBPMDI) for his insightful comments on the manuscript and Mrs. Guillermina Garcia (SBPMDI) for her technical expertise and help with quantitative microscopy. The work was funded by the Sigrid Juselius Foundation, the Academy of Finland, Päivikki and Sakari Sohlberg Foundation, Instrumentarium Research Foundation, Finnish Medical Foundation, Pirkanmaa Hospital District Research Foundation, the Finnish Cultural Foundation, Diabetes Wellness Foundation, Tampere Tuberculosis Foundation, Finnish Eye Foundation, the Mary and Georg Ehrnrooth Foundation, and the Research Foundation of Clinical Chemistry. 


\section{Author's contribution statement}

TJ and HU-J designed the research. HB and SP performed the RNA-Seq analyses. TK, MV, ER, PK, JH and TJ performed the research. TK, MV, UM, TP, ER, JH and TJ analyzed the data. MV, UM and TP performed statistical analyses. HU-J and MV contributed the genotyped mice littermates. TJ wrote the manuscript. MV, UM, TP and HB generated the figures. All authors reviewed and accepted the text of the manuscript.

\section{Legends for Figures}

Figure 1. R-Ras does not influence wound closure or re-epithelialization in skin wound healing, but R-Ras deficiency increases vascular permeability in skin wounds. WT and R-Ras KO mice were subjected to full thickness skin excision wounds. The wounds were photographed daily by a digital camera. Skin samples were collected from mice sacrificed at various time points. The skin samples were processed for histological evaluation. (A) The wound closure was assessed from digital photos using the ImageJ program and expressed as percentage of a day 0 wound size. (B) Representative digital pictures of the wounds from RRas WT and KO mice at various time points are shown for wound closure. Scale bar represents $5 \mathrm{~mm}$. (C) The area of granulation tissue was quantified by examining two microscopic sections from each wound and the results are expressed as $\mathrm{mm}^{2}$. (D) The gap between epidermal tongues was quantified by examining two microscopic sections from each wound. **, $P=0.0005$; Student's t-test. The results are expressed as mean $\pm \mathrm{SEM}$ for the A panel and mean \pm SD for the rest. (E) At day 7 of healing, Evans Blue (EB) dye was injected intravenously, and skin wounds and blood samples were harvested after $24 \mathrm{~h}$. EB concentrations were measured spectrophotometrically at $620 \mathrm{~nm}$, and EB concentration for 
each sample was calculated from a standard curve. Results are expressed relative to EB concentration in the plasma. Statistical analysis shows a significant increase in vascular leakage in R-Ras KO skin wounds compared to WT wounds at the 2-hour time point (**, $P=0.002$, Welch's t-test). The results are shown as mean \pm SD. For n-numbers see Suppl. Table S1. (F) Representative wound images of days 2, 7 and 14 are shown from both R-Ras WT and KO mice. Scale bars: $0.5 \mathrm{~mm}$ (low) and $0.2 \mathrm{~mm}$ (high magnification). Yellow lines indicate granulation tissue. Low magnification images are constructed from four (day 2) or three (days 7 and 14) separate images covering the whole wound.

\section{Figure 2. R-Ras does not have an effect on wound closure process in the splint excision} wound model. WT and R-Ras KO mice were subjected to splint skin excision wounds. The wounds were photographed by a digital camera and skin wound samples were collected from mice at day 7 and 14. The samples were processed for histological evaluation as described in methods. (A) The wound closure was assessed from digital photos using the ImageJ program and expressed as percentage of a day 0 wound size. (B) Representative digital pictures of the wounds from R-Ras WT and KO mice. Scale bar: $5 \mathrm{~mm}$. (C) The area of granulation tissue was quantified by examining two microscopic sections from each wound and the results are expressed as $\mathrm{mm}^{2}$. (D) The gap between epidermal tongues and (E) wound length were quantified. The results are expressed as mean \pm SD. For n-numbers in the experiments, see Suppl. Table S1. (F) Representative images of days 7 and 14 wounds with silicone splints are shown from both R-Ras WT and KO mice. Scale bars: $1 \mathrm{~mm}$ (low) and $0.2 \mathrm{~mm}$ (high magnification). Yellow lines indicate newly formed epidermis. 

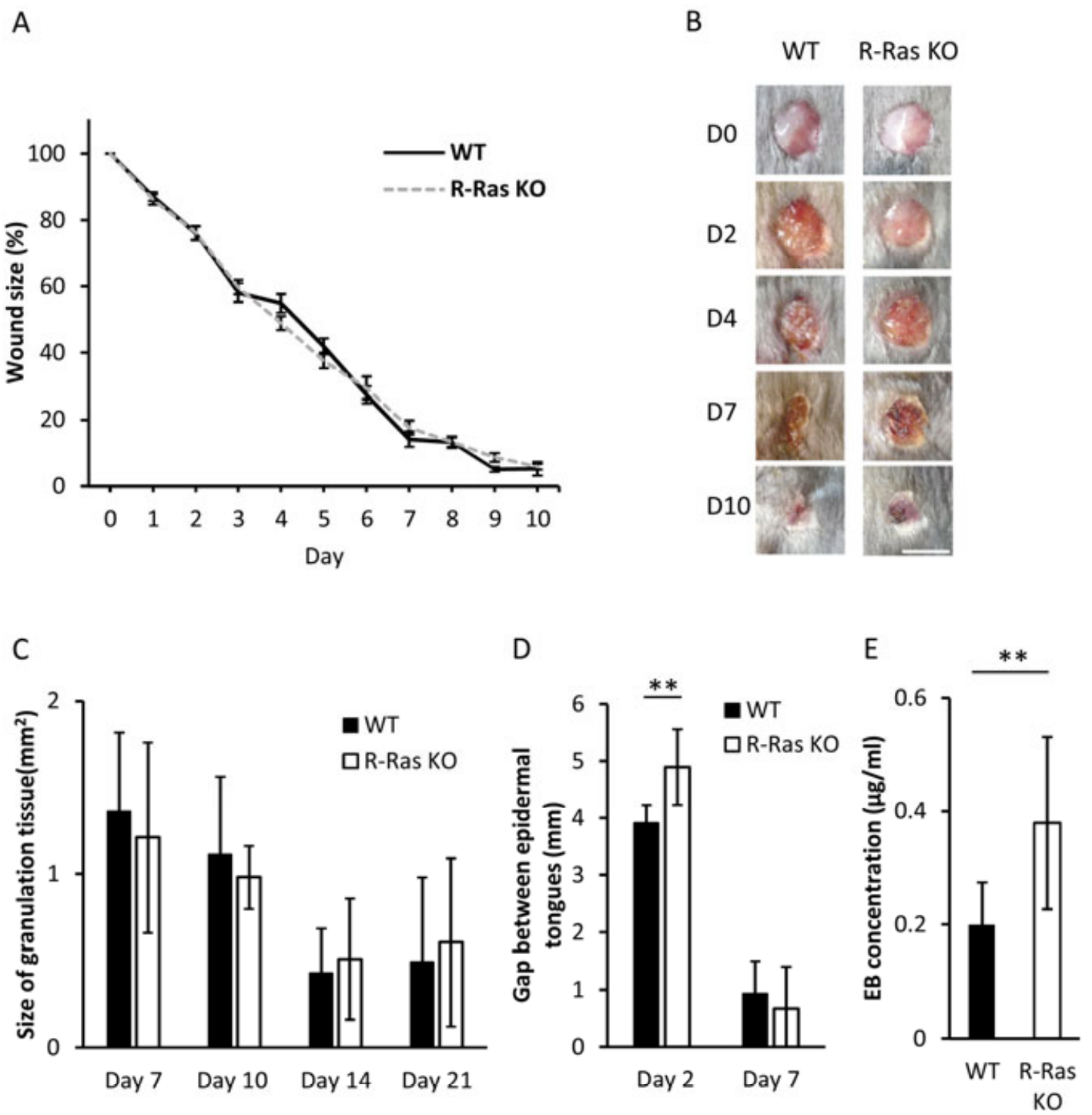

F

WT

R-Ras KO

D2
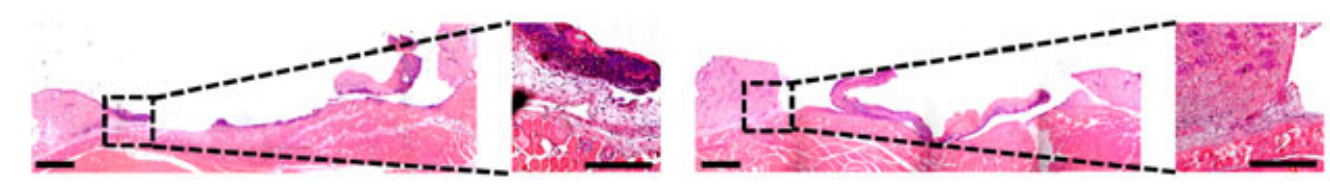

D7
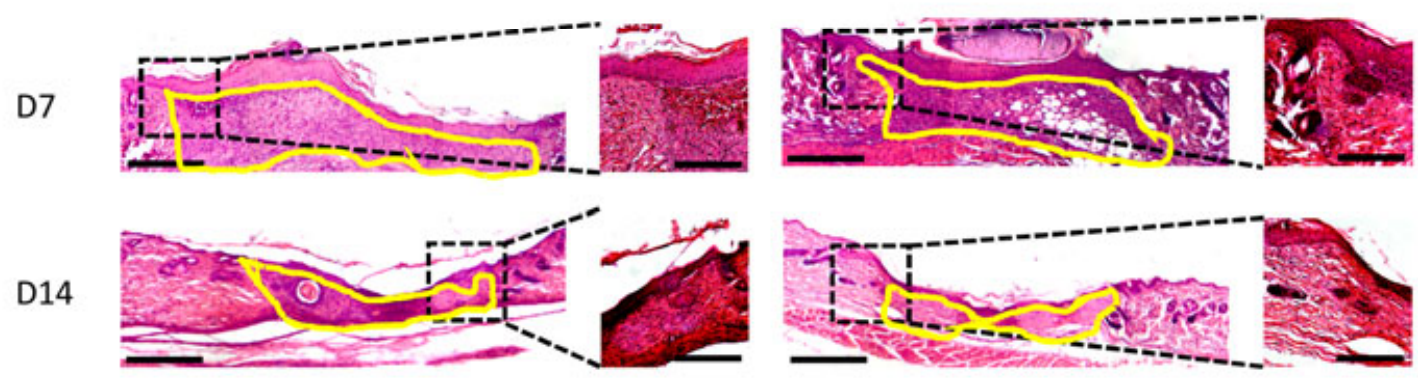

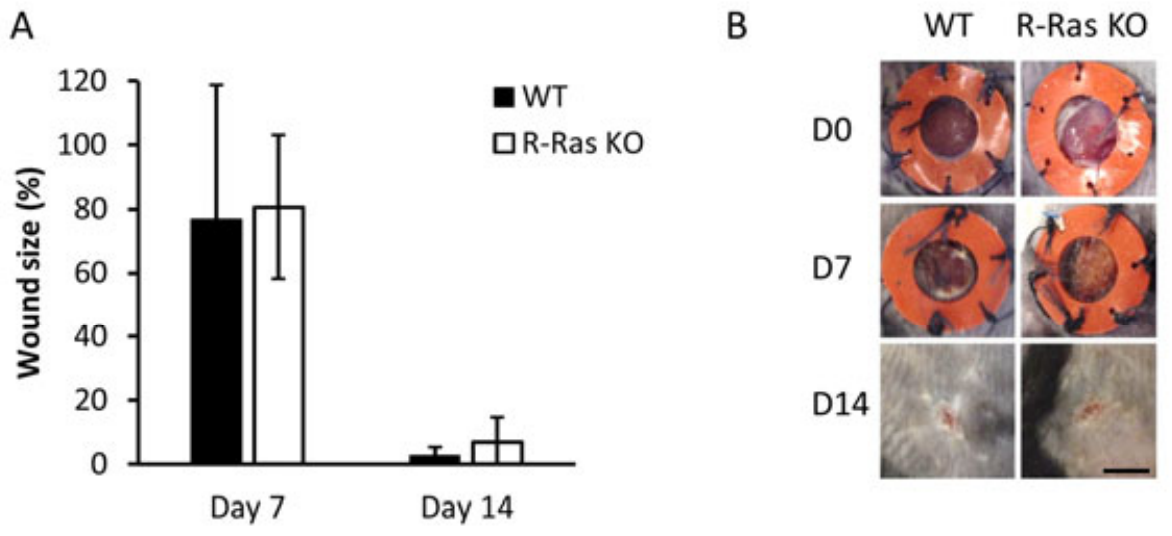

C

D

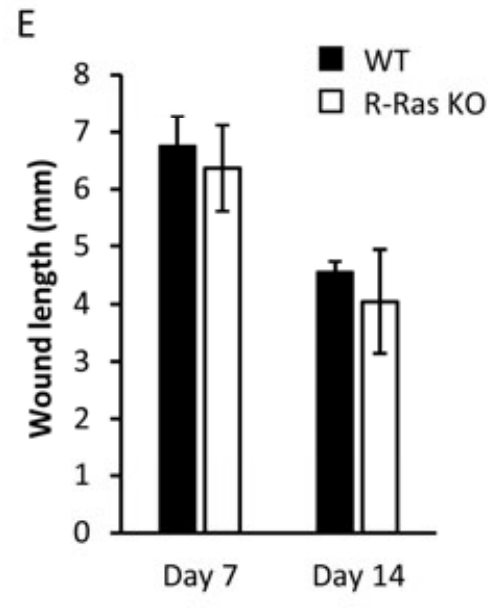

F
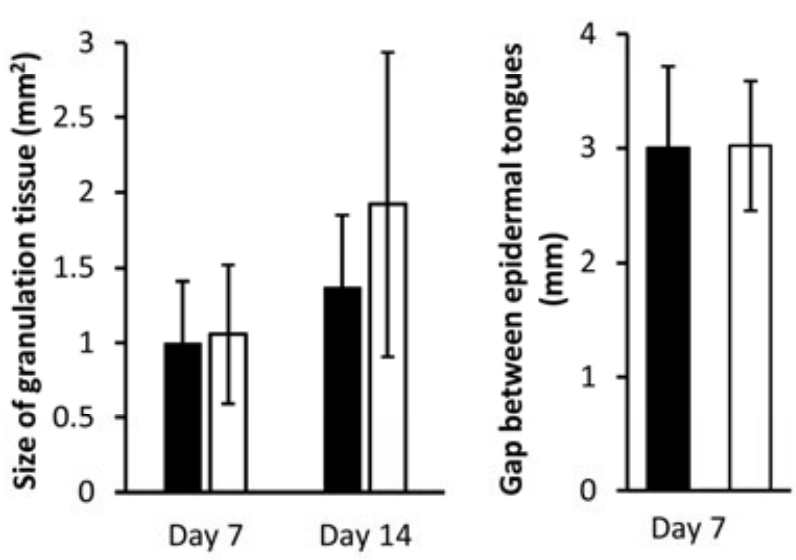

F
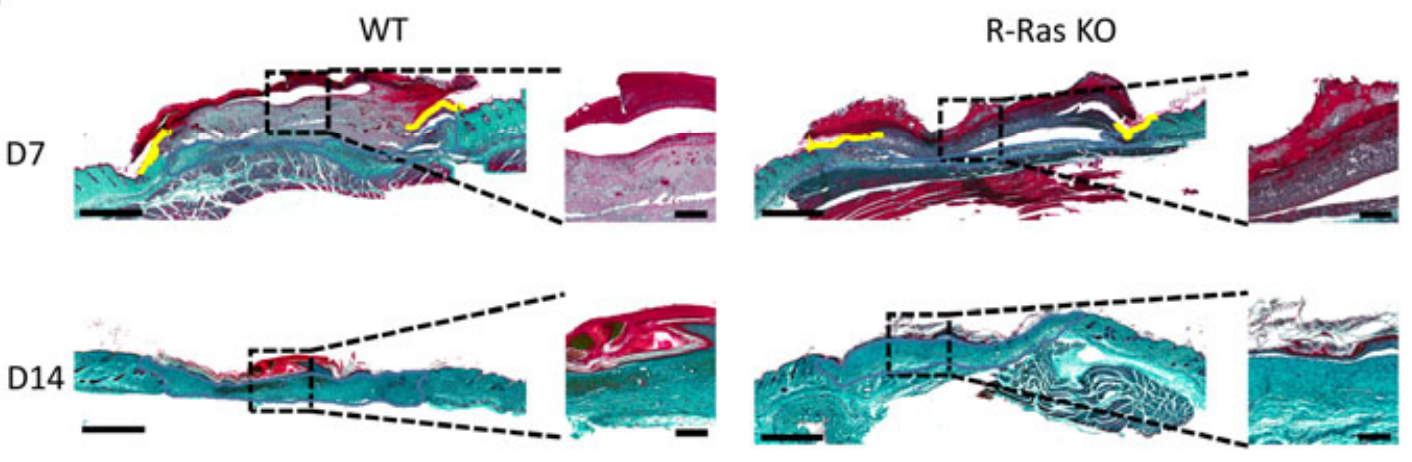